\title{
Iron in tubewell water and linear growth in rural Bangladesh
}

\author{
A Briend, B A Hoque, K M A Aziz
}

\begin{abstract}
The growth of 694 children from rural Bangladesh was studied. Children drinking water containing $>1 \mathrm{mg}$ iron/l $(n=628)$ were significantly taller than those drinking $<1 \mathrm{mg}$ iron/l $(n=66)$ : their mean (SD) height for age $Z$ score was $-2.10(1.34)$ compared with $-2.45(1.24), p<0.05$. This suggests that iron deficiency may contribute to growth retardation in poor communities.
\end{abstract}

Most underweight children in developing countries are short compared with international growth standards. Deficits in weight in relation to height are less common. ${ }^{1}$ The origin of this height deficit is still debated but it is suspected that mineral and protein deficiencies may play a part. $^{2}$ There is little epidemiological evidence, however, to support this hypothesis.

In Bangladesh, most drinking water comes from shallow tubewells. In some places, depending on the soil characteristics, water coming out of these tubewells is heavily loaded in iron. This gives a bad taste and a bad aspect to water and makes it less suitable for cooking. Iron reduces water acceptability and is often thought to be a cause of diarrhoea because villagers are tempted to use unsafe surface water when tubewell water contains iron.

In this study we examined the nutritional impact of water loaded with iron and assumed that it would be associated with increased frequency of diarrhoea and malnutrition. Our findings, however, give more support to the role of minerals to promote growth than to the hypothesis we originally tested.

\section{Patients and methods}

This work is based on data collected for the evaluation of a water and sanitation project that took place near Mirzapur, in rural Bangladesh between 1984 and 1987. Handpumps, latrines, and hygiene education were provided to an intervention area with approximately 5000 population and compared with a nearby control area. For this analysis, data from the intervention area only were analysed. In this area all households had access to tubewell water and used it, at least for drinking.

Measurements of heights and weights for nutritional assessment were made on average every three months for children below 3 years of age and every six months for children aged 3 to 5 years. Children were weighed to the nearest $0.1 \mathrm{~kg}$ on a Salter scale, which was regularly checked against standard weights. Length for children aged less than 2 years and height for older children were measured to the nearest $\mathrm{mm}$.

Nutritional indices for weight for age, height for age, and weight for height were calculated in $\mathrm{Z}$ scores, representing the difference of an anthropometric measure with the reference standard from the National Center for Health Statistics expressed in standard deviation units. ${ }^{3}$

This analysis was made with data collected in 1986 , as water was analysed for that year only. These data were collected on 694 children, with a mean age of 25 months at the first visit and seen 2.3 times on average. For 257 children $(37 \%)$ only one measure was available. As children were seen a different number of times, the nutritional state of each child was represented by its average $\mathrm{Z}$ score over the year.

Iron content of water was measured by the phenanthroline method for ferrous iron. ${ }^{4}$ The list of households using each tubewell was made at the time when water samples were collected.

\section{Results}

Children from households getting their drinking water from a tubewell with a iron content higher than $1 \mathrm{mg} / \mathrm{l}$ (upper limit for drinking water according to the World Health Organisation ${ }^{5}$ ) were slightly heavier than other children and these children had a significantly higher height for age. Weight for height was almost identical between the two groups (table 1).

Table 1 Nutritional state of children according to iron content of tubewell water used by the household. Results are mean $(S D) Z$ score

\begin{tabular}{|c|c|c|c|}
\hline & $\begin{array}{l}\text { Weight } \\
\text { for age }\end{array}$ & $\begin{array}{l}\text { Height } \\
\text { for age }\end{array}$ & $\begin{array}{l}\text { Weight } \\
\text { for height }\end{array}$ \\
\hline $\begin{array}{l}\text { Iron content of } \\
\text { tubewell water: } \\
<1 \mathrm{mg} /(\mathrm{n}=628) \\
>1 \mathrm{mg} / \mathrm{l}(\mathrm{n}=66)\end{array}$ & $\begin{array}{l}-2 \cdot 28(0.99) \\
-2 \cdot 08(1 \cdot 20)\end{array}$ & $\begin{array}{l}-2 \cdot 45 \\
-2 \cdot 10\end{array}$ & $\begin{array}{l}24)-1 \cdot 06(0.79) \\
34)^{*}-1 \cdot 11(1.01)\end{array}$ \\
\hline
\end{tabular}

${ }^{*} \mathrm{p}<0.05$ compared with children drinking water low in iron.

Table 2 Height for age of children according to the iron content of tubewell water in different age categories. Results are mean $(S D) Z$ score

\begin{tabular}{lll}
\hline Age (months) & \multicolumn{2}{l}{ Iron content of tubewell water } \\
\cline { 2 - 3 } & $<1 \mathrm{mg} / \mathrm{l}$ & $>1 \mathrm{mg} / \mathrm{l}$ \\
\hline$<12(\mathrm{n}=216)$ & $-1 \cdot 51(1 \cdot 10)$ & $-0.94(1 \cdot 40)$ \\
$12-23(\mathrm{n}=119)$ & $-2 \cdot 66(0.86)$ & $-2 \cdot 18(1 \cdot 04)$ \\
$24-35(\mathrm{n}=133)$ & $-2.83(1 \cdot 05)$ & $-2 \cdot 19(1.07)$ \\
$36-47(\mathrm{n}=117)$ & $-3.06(1 \cdot 08)$ & $-2.67(1.27)$ \\
$\geqslant 48(\mathrm{n}=109)$ & $-3.06(1 \cdot 10)$ & $-3.08(1 \cdot 14)$
\end{tabular}

Two way analysis of variance-main effects: iron, $F=7.91$ and $p=0.005$; age, $F=24.61$ and $p<0.0001$; interaction term: $\mathrm{p}=0.68$ and $\mathrm{p}=0.60$. 
Adjusting the effect of iron by two way analysis of variance for age, the number of visits, land holding or for the possession of a watch or a radio, or for the level of education of the household head did not reduce the strength of the association between the iron content of tubewell water and height for age.

The effect of iron water on height seemed to be more pronounced in younger children who, on average, were significantly less stunted (table 2). Yet a two way analysis of variance failed to show a significant interaction between age and iron content of water, which means that the effect of iron was not significantly greater in younger age groups.

\section{Discussion}

The association reported here between the iron content of drinking water and linear growth may be coincidental or due to some unknown confounding factors. Confounding, however, seems unlikely. Iron concentration in drinking water depends on soil characteristics and high concentrations occur in clusters of tubewells independently of other factors determining nutritional state. Age of the tubewell was considered as a potential confounder as tubewells with a high iron content were often old models installed by slightly better off families before the project started. However, adjusting for other socioeconomic indicators did not change the association between iron and height. In addition, each tubewell was usually used by several families of different socioeconomic status.
In this community diet is based on rice and contains virtually no animal protein. Presumably, most of these children were iron deficient, both as a result of a low intake and of a low absorption of iron. Iron coming from the tubewell was in ferrous form, which is likely to be well absorbed, especially if taken between meals. We suspect we observed on a quasi experimental basis at the community level, the growth promoting effect of iron, which has been recently reported from a clinical trial. ${ }^{6}$

Further studies are needed to confirm our findings. Other minerals present in the soil along with iron, and not iron itself, may have promoted linear growth. Our observations, however, support the hypothesis that the mineral content of the diet may be an important determinant of linear growth.

Dr A Briend was seconded to the International Centre for Diarrhoeal Disease Research, Bangladesh by ORSTOM, Institut Français de Recherche Scientifique pour le Développement en Coopération, France.

1 Keller W, Fillmore CM. Prevalence of protein energy malnutrition. World Health Stat Q 1983;36;129-67.

2 Golden MHN. The role of individual nutrient deficiencies in growth retardation of children as exemplified by zinc and growth retardation of children as exemplified by zinc and protein. In: Waterlow JC, ed. Linear growth in less

3 countries. New York: Raven Press, 1988:143-60. metric indicators of nutritional status. Bull WHO 1986;64: 929-41.

4 Anonymous. Water analysis handbook. Loveland, Colorado: Hach Company, 1982.

5 Anonymous. International standards for drinking-water. 2nd Ed. Geneva: World Health Organisation, 1963.

6 Aukett MA, Parks YA, Scott PH, Wharton BA. Treatment of iron increases weight gain and psychomotor development. Arch Dis Child 1986;61:849-57.

\title{
The five year school medical-time for change
}

\author{
G C Smith, A Powell, K Reynolds, C A Campbell
}

\begin{abstract}
School medical records of 1000 children born in 1981 were studied retrospectively. They showed that once known medical problems and those screened for by the school nurse (hearing, vision, growth) were excluded, only 17 problems requiring treatment were discovered: speech $(n=10)$, development $(n=3)$, undescended testes $(n=3)$, and phimosis $(n=1)$. This indicates that routine screening by a nurse, backed up by selective medical examination by the school doctor, is efficient and effective.
\end{abstract}

Department of Paediatrics, City Genera Hospital, Stoke-on-Trent G C Smith A Powell K Reynolds C A Campbell

Correspondence to: Dr C A Campbell, City General Hospital Newcastle Road Stoke-on-Trent ST4 6QG.

Accepted 4 September 1989 to perform these medicals at any particular age. This has left individual community health departments to initiate their own programmes of screening checks at various ages. At present, in the North Staffordshire district all children are screened at the age of 5 years, on primary school entry. Before the examination a questionnaire is sent to the parents inquiring about any known medical problems or any worries they have regarding their child. The school nurse performs an audiometric assessment using pure tone audiometry, tests visual acuity using the Sheridan Gardner single letter cards (STYCAR), and measures height and weight. The school doctor then sees the child, ideally in the presence of a parent and performs a physical examination and a basic neurodevelopmental assessment including speech. Until four years ago, children also routinely received a medical at the age of 16 years, before leaving school. This is now a selective medical for children known to have medical problems or those who are thought by the parent, teacher, or school nurse to warrant a medical. Again a parent questionnaire is sent before this selection process.

We wanted to discover whether the present 